\title{
A Discourse Setting Phenomenon and Its Implications in Literature
}

\author{
Keqing Chai \\ School of Foreign Languages \\ Jiujiang University \\ Jiujiang, China \\ e-mail: ckqaie@126.com
}

\author{
Yang Liu \\ School of Foreign Languages \\ Jiujiang University \\ Jiujiang, China
}

\author{
Yan Zhang \\ School of Foreign Languages \\ Jiujiang University \\ Jiujiang,China
}

\begin{abstract}
Based on Bakhtin's theory of discourse setting, the thesis analyzes discourse setting phenomenon in college English textbooks from the intrinsic elements and the basic characteristics of the discourse setting theory. And the thesis analyzes three aspects: background setting, language setting and thoughts setting, which not only helps readers understand English literature better, but interprets the works of English textbooks from a new perspective.
\end{abstract}

Keywords - dialogue; setting; discourse setting theory; English literature

\section{Theory OF Discourse SETTING}

The 20th century was the century of literary criticism. All kinds of genres of literary criticism, like kaleidoscope, dazzled the sense of people. In a hubbub, a famous name frequently appearing, he was M. M. Bakhtin, the famous literary theorist of the former Soviet Union. He raises a series of unconventional theoretical issues, such as polyphonic novel theory, dialogue theory, carnival poetics theory, which are continually explored by the people. And discourse setting theory, one of its core theories, is helpful for the readers to understand and deconstruct English literature.

Chai Keqing believes that discourse setting theory is the highest stage of Bakhtin.

Liu Yang (1978- ), female, lecturer, School of Foreign Languages, Jiujiang University (JJU), Jiujiang, China.

Zhang Yan (1983- ), female, lecturer, School of Foreign Languages, Jiujiang University (JJU), Jiujiang, China.

discourse studies. Chai Keqing proposes a discourse setting theory through depth study of Bakhtin ideological discourse, especially in the historical development of Bakhtin's theory of discourse - from discourse to discourse setting (Chai Keqing, 2013), which comprehensively elaborates historical development of discourse setting theory, has made a thorough analysis and summary about the

[Research Project: Jiangxi social science planning special issue of foreign language teaching and research university in Jiangxi 2012, item number $12 \mathrm{ww} 402$. connotation and features of theory setting discourse. Discourse setting theory is derived from Bakhtin's many works, such as Life discourse and artistic discourse, Marxism and the philosophy of language, novel discourse, and so on. Among the series of writings Bakhtin proposes discourse, discourse paraphrased and relayed, discourse setting and other important elements of discourse setting. And from the multi-dimensional and multi-level respects Bakhtin also discusses and explores each element of the discourse and the discourse related, such as related words, meaning, evaluation, tone and emotion. Bakhtin Setting put forward three important features: First, the background setting. Language is social in nature, always with the social information, marked by the stigma of society, The speaker has his own social background, for all his words are associated with the speaker's social background and attitudes closely, therefore other discourses and discourse contexts of the speaker's dialogue must include others people's words; Second, speech setting, speech itself is just a vehicle for communication, the premise of meaningful communication is the human social interaction and argument with the personality, which is a process without beginning or end, and thus words of the social discourse must be set with other people's discourse; Third, the ideological setting. Each discourse contains the words of other's, each of the words is a dialogue, communicates with others and struggle.

\section{INTERPRETATION OF LITERARY SETTING}

The real life of language is not the language system itself, not the language structure of the relationship between the various components, but the discourse, which belongs to specific individuals. Specific performance: First, any individual's words includes his conscious intentions, which is his social behavior, accesses to personal social existence. Second, the discourse is the representative of the individual involved in linguistic communication, so it is always unique, and quite different from other individual's similar words. But it is certainly set with the words of other people's, and never unique. Overtone in conversation leads to another more 
important idea--- the essence of dialogue discourse. Discourse meaning initiation, its fulfillment, its elaboration and its respondence can only occur in the language communication between discourses with others, which exchanges freely and equally. It thus forms a dialogue with dialogist's words. This dialogic discourse, both represents the nature of the human mind and the nature of individual consciousness dialogue .It not only reflects in the literary works of narrative structure but also all texts throughout the humanities in the whole process of creating and receiving texts. It tells us a new side from the humanities to understand the essence and methods. This article analyzes All the cabbie had was a letter, (hereinafter referred to as $A C H W L$ ) from the three aspects from college English textbook with Bakhtin's discourse setting theory. $A C H W L$ is a college English text, which comes from Boston Magazine (1985). The article describes an incident between passengers and the taxi driver, which expresses the implication whether it is necessary to keep in touch frequently when old friends are apart? Sometimes it is liable to delay writing to friends, always count on tomorrow, and the dialogue between the passenger and taxi driver of the story urges people to take their pens to get in touch with old friends. This sets the performance of readers and literary phenomenon. $A C H W L$ demonstrates setting phenomenon everywhere, and the thesis interpret $A C H W L$ from three aspects: the background, the language and the ideas setting.

\section{A. Background setting}

Background setting means that language has its own background, not existing in society alone. Any discourse must be related to the speaker's social background and his attitudes, which we need to understand from multiple social contexts. As in the works $A C H W L$, at the beginning of the article. "I got on the taxi, the driver was reading the letter, 'I am in no hurry,' I said to him", 'Go ahead and finish your letter' He shook his head, 'I have read it several times already. I guess I almost know it by heart." Letters from home always mean a lot,' I said." This part contains the passenger himself understandings on letters from home. If the passenger did not have this experience, he would not have the emotion and the conversation between the cabbie and the passenger would not have happened. So the speaker's life is an important prerequisite for the smooth development of the discourse. And later when the passenger knew that the driver had lost a cherished old friend of his on the way to hotel, the passenger responded according to his own experience: it is really bad losing a friend, and it is more unbearable losing a true friend. It is with the same rich experience of his that the passenger responds the taxi driver. All of these formulas, which are set with both the speaker and hearer of their psychological state and social status, that are psychological and ideological, internal and external background, no matter how subtle they are, are vivid reflection of dialectical synthesis in achieving the realization of the dialogue. "I "(the author), the passenger and the taxi driver, understood each other. For example, when the passenger saw the driver being engrossed into a letters, the "I" asked him to read the letter continually, this understanding shoud contain his own background ----the feelings of reading letters. Without the experience, the passenger would not have this sense and even would not release the sighs: "It is more unbearable losing a true friend." This is a subjective experience embedded in discourse, and directly affects the performance of social forces.

\section{B. Language setting}

Language setting means that any word any person says in society is repeating the words of other's. Bakhtin emphasizes that the nature of language is dialogic. He proposes that the discourse itself is just a vehicle for communication. language, which is used in many fields (in daily life, official exchanges, scientific, literary,etc.). "All of these are permeated with language setting" (Bakhtin 1998:5:242 ). In ACHWL, the passenger said: "I do not think any of us keeps up our correspondence too well," "There are not too many people who have had such a long friendship" " We should all keep well in touch with old friends ." Again, " The letter said that I have been meaning to write for some time, but I have always postponed it. And just few of us are still alive." The passenger replied, " It's true right, every time I go to a class reunion, for example, there are fewer and fewer still around." This time the driver responded," time goes by. "All of these fall into the discourse setting according to M. M. Bakhtin. From the discourse setting theory, the reader can feel the passenger's remarks not only to the taxi driver, assent to the taxi driver's words but more to themselves .The discourse to others containing their own thoughts. The speech of the driver is not just to the passenger, but also to himself, to the old friend who has already died. These words are inlaid with each other. It is the important aspect of the discourse that Bakhtin emphasizes, which is the proof of a certain relationship between "I" and "others", and further demonstrates a innate setting relationship of human languages. From the perspective of understanding the language setting, the reader can feel the meaning and emotion contained in the words of the speaker.Just as Bakhtin has put forward, we have many profiles of ourselves both in ourselves and among a group .The dialogue features self and group identity, which means we, by talking with others, or hearing our internal voice, build ourselves.

What is more, thoughts setting shows that dialogue is not simply a human interaction, which is an interactive verbal behavior, but rather a setting of discourse with each other and generates a force behavior. Here the power of words is the importance from others to ourselves. Only by observing others, can people construct self-awareness, the process of self-consciousness. When composing, the most important of his behavior is to determine the relationship of consciousness to others, which represents the language setting.

\section{Thoughts setting}

Ideological discourse mosaicism including each verbal expression can be manifested in attitudes and values, which are embodied by its cultural and historical constraints; therefore, whether the words are spoken phrases or written expressions, the speech is a particular point of view or perspective to express the speaker's ideas. As Bakhtin proposes that the ultimate goal of the dialogue is to complement each other in dialogue and communication, seek development and innovation. Based on the idea mosaicism, readers can have a better grasp of the language of the article. As described in the end of the article," When I got to the hotel 
room I did not unpack right away. First I had to write a letter--- and mail it.", This description, which is the passenger's final monologue, produces many rich ideological influence from the perspective of discourse setting. If passengers embed the idea or experience of having parted his friends for many years without contacting, or each contacting being always delayed due to various reasons, many more readers will participate in interpretation. It will have a unique sound setting with a number of readers', bringing a variety of unique perspective, and this can help readers develop their individual voices, exchange ideas to reflect the ideological value better.

So thought processes are involved in the performance of dialogue setting, which is a creative process. In this process people are interacting. And the interactive way shows the diversity and richness, collaboration and creativity. And it is this creative human practice and sustained value creation process that we have a unique human social activities.

\section{ENLIGHTMENT}

Bakhtin's discourse setting theory has broken the isolated personal background when individuals are involved in verbal communication. Discourses can be the same theme shared by two or more parties, engraving or printing two or more parties background and experience of the dialogue. Any discourse is a work of complex setting and the inlay of discourse provides a new dimension to the readers. The more readers interpret works from the background setting, language setting and thought setting, the better readers will be able to understand the authors and work, and more important, it will have effect and power on readers thinking and their language. Of course, the interpretation of the work should be ambiguous, and any kind of interpretation cannot exhaust its full meanings. For this reason, the analysis of discourse setting not only brings the fresh to the analysis of works, but more important, discovers a larger space for people to explore.

\section{REFERENCES}

[1] Bakhtin. Bakhtin Complete Works (3 volumes, in translation) [M], Qian Zhongwen Chinese editor, Hebei Education Press, 1998.

[2] Bai Chunren: Discourse on the edge - Bakhtin Discourse Theory Analysis [J] Foreign Language Teaching and Research .2000 (3).

[3] Lin. Reflections on Bakhtin'. PLA UNIVERSITY OF FOREIGN LANGUAGES [J]. 2005 (7).

[4] Tan Fang. Exploration of Bakhtin's in Foreign dialogue classroom. Northeast Normal [D] .2012 (6).

[5] Chai Keqing Historical development of Bakhtin's theory of Discourse. Jiujiang University (Social Science) from discourse to discourse mosaic. [J] .2013 (4) 